\title{
Bringing Building Information Modeling (BIM) into the Process for Building Structure Design Courses
}

\section{Prof. John J Phillips P.E., Oklahoma State University}

JOHN PHILLIPS, a registered engineer and associate professor of architectural engineering, practiced as a structural engineer for nine years before returning to his alma mater to teach at Oklahoma State University. He teaches undergraduate and graduate courses to architecture, architectural engineering, and civil engineering students that include Statics, Analysis I, Foundations, Timbers, Steel, Concrete, Masonry, Steel II, Concrete II, Steel III, Concrete III, and the Comprehensive Design Studio.

Jenna A Harbert 


\title{
Bringing Building Information Modeling (BIM) into the Process within Building Structure Design Courses
}

\begin{abstract}
Building Information Modeling (BIM) is a powerful tool that is widely utilized in the architecture, engineering, and construction (AEC) industries in the United States for the design and construction of buildings, and is becoming prevalent worldwide. The BIM model can be used not only for architectural design, but also to analyze, design, and monitor multiple systems within a building. The structural engineer will keep a BIM model up-to-date with structural information as part of the design team requirements, but they must also model the building structure in separate programs for the purpose of structural analysis and design. This requirement for modeling the building twice is an inefficient use of resources, especially since a BIM model has the capabilities of aiding the structural design process through interfacing with those separate programs.

Utilizing a BIM model for the purpose of structural analysis and design is a topic that needs to be explored to understand its limits of application, and how it can be taught to students who will become part of the AEC industry upon graduation. Research on this topic will allow for discoveries on how and what to teach students, as well as what industry feels the new graduates should know pertaining to the subject. This paper will explore the use of BIM within the structural design process for Architectural Engineering programs. It will include a literary search on the use of this method in higher education, and will detail the process in which it is introduced into intermediate design courses in steel and concrete, with student assessment of the process.
\end{abstract}

\section{Introduction}

There is a need for advances in technologies used in the profession of engineering to be included in the educational process in higher education, however the question arises as to the extent of this inclusion. With the vast number of topics that engineering students must be taught during their educational career, the addition of new technologies is at times difficult to accomplish in a productive manner. The argument for the inclusion of new technologies in teachings is that upon graduation, interns entering the profession will be required to utilize these in the analysis and design process. The opportunity for introducing students to these technologies during their education will give them a look into the profession they will be joining upon graduation, and will better prepare them and make them more marketable as engineering interns. As this topic pertains to the education of structural engineers, the use of BIM to aid in the design of building structures is one that continues to evolve in the profession, and one to which students should be exposed to during their education.

A literary search conducted on the topic of BIM for the use of structural engineering design, and little was found in the way of research being performed on this topic. There were a number of publications that discussed BIM for use in educational purposes, however very few were discovered that pertained to the use of BIM in structural engineering design education. One notable exception to this was a publication that looked at when BIM should be introduced to students in higher education. Results from that study indicated the inclusion of BIM into civil and architectural structural engineering courses gave students an advantage at better understanding the systems and the process of design and documentation [1]. Students in engineering often have expectations that they will be introduced to current technology that can enhance their skills and knowledge on a particular subject [2]. 


\section{Overview of Curriculum}

The Architectural Engineering program at Oklahoma State University is a five year undergraduate program that is professional practice based in its teaching approach, and is team taught. Within the curriculum there are introductory courses in timber, steel, and concrete structure design that are taken with architecture students. For this program, the number of required structural analysis and design courses are more than typical for an undergraduate program in Architectural Engineering, and this is possible due to being a five-year undergraduate program. The extra year allows for the inclusion of additional required structural engineering courses that make our graduates both marketable to the profession and good candidates for graduate programs. Once complete with the introductory structural design courses, the Architectural Engineering students continue with required structural design courses in classical analysis, masonry, foundations, and intermediate steel and intermediate concrete design. It is in these final two courses that the introduction of advanced technologies can happen and be used to streamline the process of structural engineering, and to better prepare students for professional practice where knowledge of these emerging technologies will allow them to be positioned to immediately contribute as engineering interns.

\section{Multi-story Building Structure Design}

In the intermediate structural design courses for both steel and concrete, the format of each focuses on a semester long project in which a multi-story building structure is designed using a three-dimensional modelling program, and is documented using BIM. The first of these courses in the curriculum flow is Intermediate Steel Design during the third year of the program. For this course the building parameters (dimensions, number of stories, bay sizes, ...) are set by the Professor and each student is expected to utilize their knowledge from the first steel design course along with added teachings during the semester to design and document the structure for

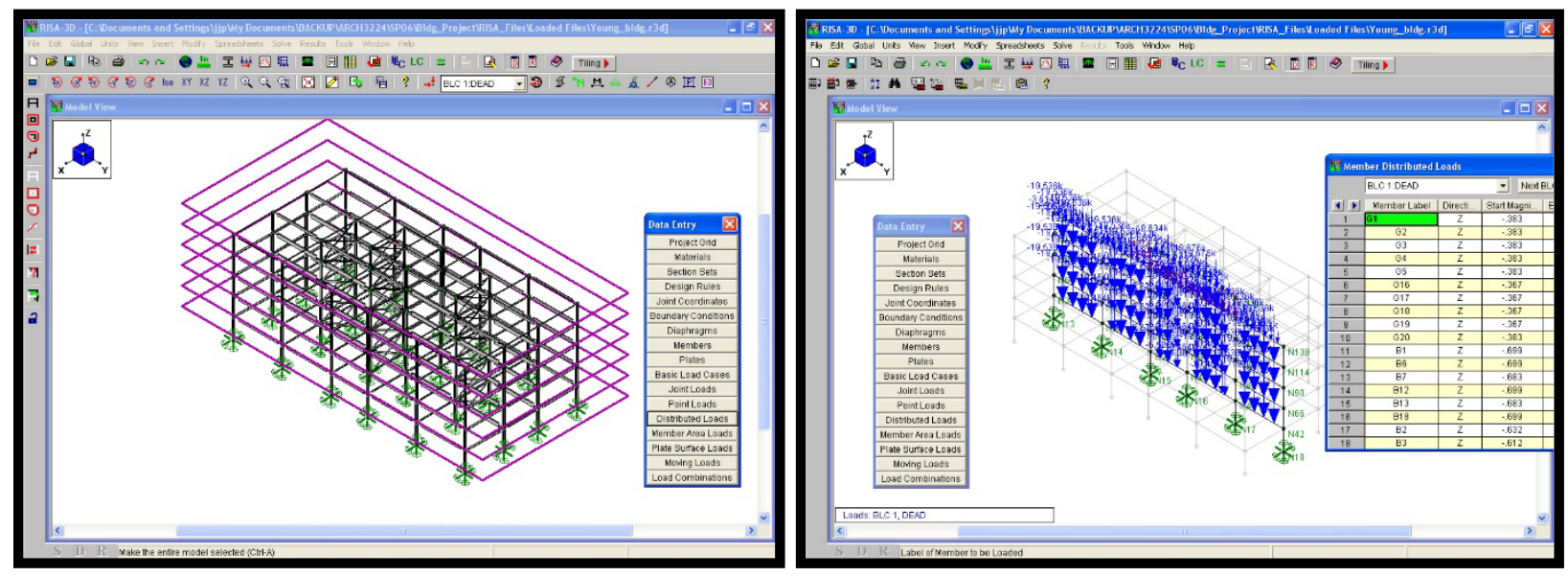

Figure 1: Students learn to utilize the RISA-3D Program during the semester project [3]

the building [4]. The three-dimensional modelling program currently being used for designing the structure is RISA-3D (refer to Figure 1), and is taught to the student during the semester. The process includes modelling the structures dimensions and constraints, inputting the structural members, setting the material design parameters, calculating and modelling the gravity and lateral forces supported by the structure, and inputting the various building code load combinations required for analysis and design of the building structure. Additionally, the process 
of documenting the structural design is taught once the final member sizes have been determined, and this documentation is accomplished through the use of a BIM program. The process of introducing these new tools properly is time consuming to teach at a pace in which the students will not be overwhelmed and stretches over the entire semester. Because of this, trying to introduce how a BIM model can be imported into a structural design program is not fully covered in this first course, though an example of the technology is presented during the semester. This example is presented after the students are fully immersed in the structural software so they are able to see the time saving potential of incorporating a BIM software into the process of structural design.

For the Intermediate Concrete Design course, which occurs a year later during the fourth year of the curriculum, student take on a similar project for the design of a multi-story building structure, but this course centers on a reinforced concrete structure. The process involved in the course is similar to the course taken a year before, thus in this course there exists time to introduce BIM for the purpose of structural design instead of the required RISA instructional lectures. A BIM model is developed prior to the start of the course that all students have access to and that will be used to establish a large part of the three-dimensional design model. The process of interfacing a BIM model from Revit with the RISA-3D program is one that will allow one model to be used for dual purposes - modelling of a building design, and modelling of the structure for the purpose of analysis and design.

\section{Interface Process}

The Risa-Revit link allows for round trip changes (importing the model back and forth between programs) between a BIM model and a structural analysis /design program. The Revit model can be transferred to the Risa-3D program through a link that allows information from the BIM model to be converted into a structural model. This link is easily downloaded and free, making the tool readily accessible for use in education. Changes in the BIM model to geometry, loads, members and other design parameters can be imported into the structural model, largely avoiding the time involved in correcting or making a separate structural model.

\section{Introduction of BIM and RISA to Students in Intermediate Steel Design}

At Oklahoma State University, the Intermediate Steel Design course during the spring semester of the third year of the curriculum includes the first use of the RISA-3D software by students, while they also learn the BIM program Revit in a separate course during the same semester. Prior to this course, students have been taught the basics of the design of structural components (slabs, beams, girders, columns) through hand calculations. For many collegiate programs, RISA 3D is the software utilized to analyze gravity and lateral loads supported by building structures. In this course, students are given rough drawings of a building with set dimensional parameters, and each student is required to model the structure using RISA-3D. Further, students will determine preliminary member sizes through hand calculations, calculate loads (dead, live, snow, wind, and seismic) and determine and model code required load combinations. Once the modelling process is complete, the structural model will be analyzed for strength and serviceability, and member sizes will be revised until the structure meets the project and code requirements. After the building has been designed, students put together a set of construction documents using BIM that fully identify the required member sizes, and includes a 
number of schedules, sections, and details associated with the project. This experience closely approximates the workflow of a licensed structural engineer, and gives students an experience similar to what they will be doing upon entrance into the profession.

Though not included as a requirement for this first multi-story based structural design course, it is important that the link between a BIM model and RISA be shown and explained to students. At the end of the semester, this link is presented to the class to explain how a BIM model can be used in an efficient manner to aid in the structural engineering process. A short tutorial is presented (Figure 2) explaining the link between the two programs, and how this interface can be useful in the profession. The presentation allows students to realize they can potentially save countless hours avoiding remaking a model in a design software when a BIM model can be imported into RISA through a simple link. Student reactions included both displeasure at not being informed of this tool earlier in the process, and a desire to learn more about the link and its ability to be used in projects going forth.
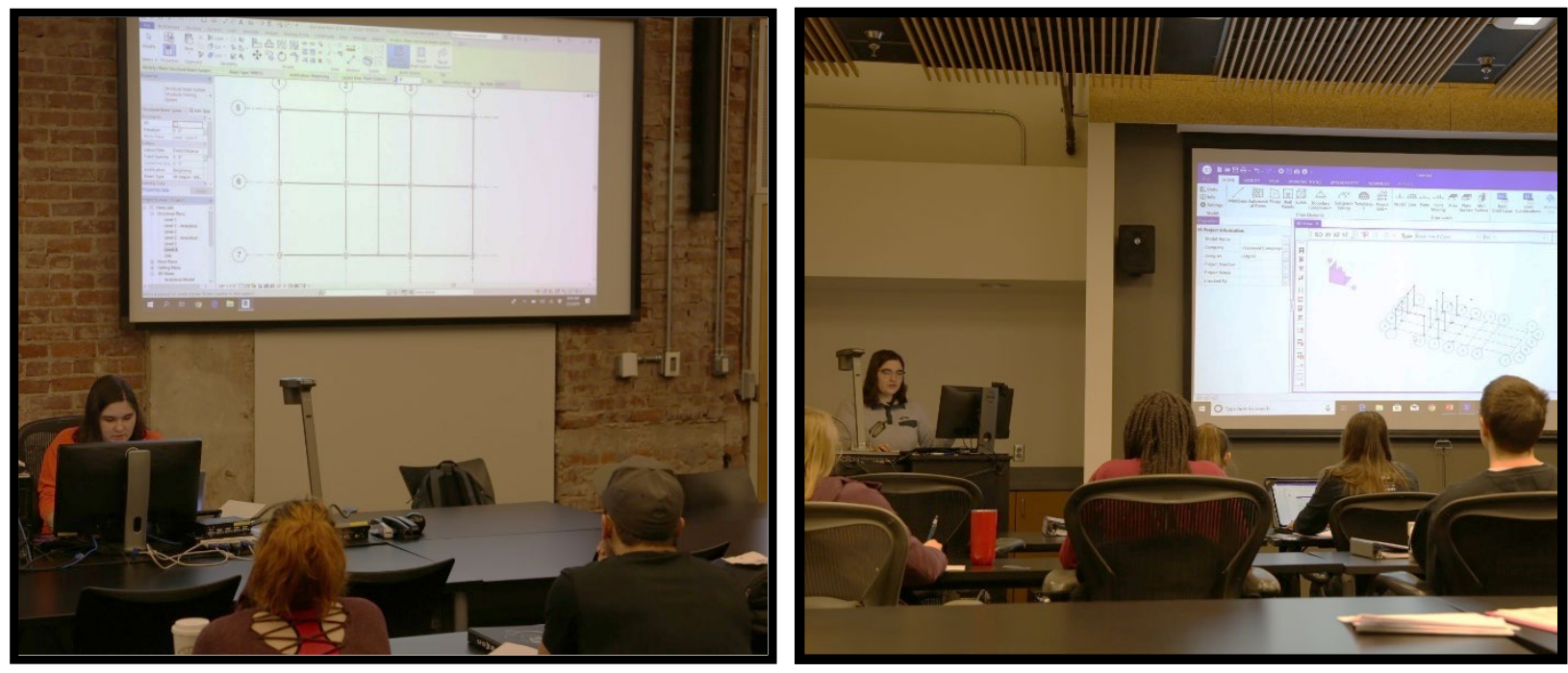

Figure 2: Student researcher introducing RISA to students in the course

From an educational standpoint, the use of this link in the Intermediate Steel course could not be accomplished due to the plethora of design aspects that must be covered in the course. Since students are learning BIM during the same semester in the curriculum, the aspect of using one model for dual purposes could not be achieved as students will not know BIM well enough until the end of the semester to model a building sufficient enough so that it could be interfaced with RISA. However, the use of a BIM model for the purpose of aiding in the structural design process could be included in the Intermediate Concrete course.

\section{BIM and RISA in the Intermediate Concrete Design}

For the Intermediate Concrete Design course, students are again shown the process involved of taking a BIM model and importing it into the RISA program to establish a structural model for the semester project. The BIM model utilized for this procedure is provided to the students based on parameters established for the semester by the Professor. By starting the semester with the BIM model available to students, they are able to proceed immediately with the process of interfacing the BIM model with RISA. Once the interface with RISA has been completed, the additional parameters needed to complete the structural model are input. The format of this course is similar to that of the 
Intermediate Steel Design course. One difference is that the project BIM model is made available at the start of the semester to students to give them time to work on additional aspects of a multi-story structure design they were unable to include in the Intermediate Steel Design course.

The incorporation of BIM into the process of structural design is one that in the opinions of the authors can enhance the educational experience of students in higher education, and can benefit engineering graduates upon entrance into the profession. However, there is a need to further explore this point of view. As part of the research on this topic, multiple surveys were performed to ascertain a better view of the current state of this topic as it pertains to engineering programs, the engineering profession, and to the undergraduate students in our program to whom experience its use.

\section{Surveys of Structural Engineering Programs, Engineering Firms, and Students}

As part of the research on this topic it was important to reach out to engineering programs and to practicing professionals for input on the availability and expectations for the inclusion of these emerging technologies. The research involved looking into how much on this topic other educational programs are covering, the extent to which the technology is included in the coursework, and when it occurs in the curriculum if included. Practicing structural engineering firms were surveyed to better understand their expectations and needs for the new engineering hires into the profession, and whether it is a requirement for being hired to understand this technology and these programs. One additional survey involved students exposed to this new technology. Students were asked to respond to a series of statements pertaining to the inclusion of BIM for the purpose of structural design as part of the intermediate design courses taught within the authors' program. With the data from the results of these surveys, a plan can be formulated for the inclusion of these new technologies into the teachings of engineering students.

For the survey sent to engineering programs, the 24 ABET accredited architectural engineering programs were contacted, as well as similar programs at other universities. A total of 32 programs were sent the survey, with 20 responding. Of those responding to the survey, sixteen are 4-year Bachelor programs, two are 5-year Bachelor programs, and two are combined 5-year integrated Bachelor / Graduate programs [5].



Figures $3 \mathrm{a}$ and $3 \mathrm{~b}$ : Engineering program survey results on the inclusion of BIM and engineering programs From the survey results (Figures $3 a$ and $3 b$ ) it can be seen that the majority of programs include BIM 
to some extent as part of the curriculum. The inclusion of BIM in the curriculum was anticipated due to the close relationship of most programs with architecture, a profession that uses BIM extensively. Additionally the survey revealed that Revit is the predominant BIM software included in those curriculums in which it is included. A reason for this may be that the Revit program is free for educational use to students and faculty, in addition to being widely used in the professions.
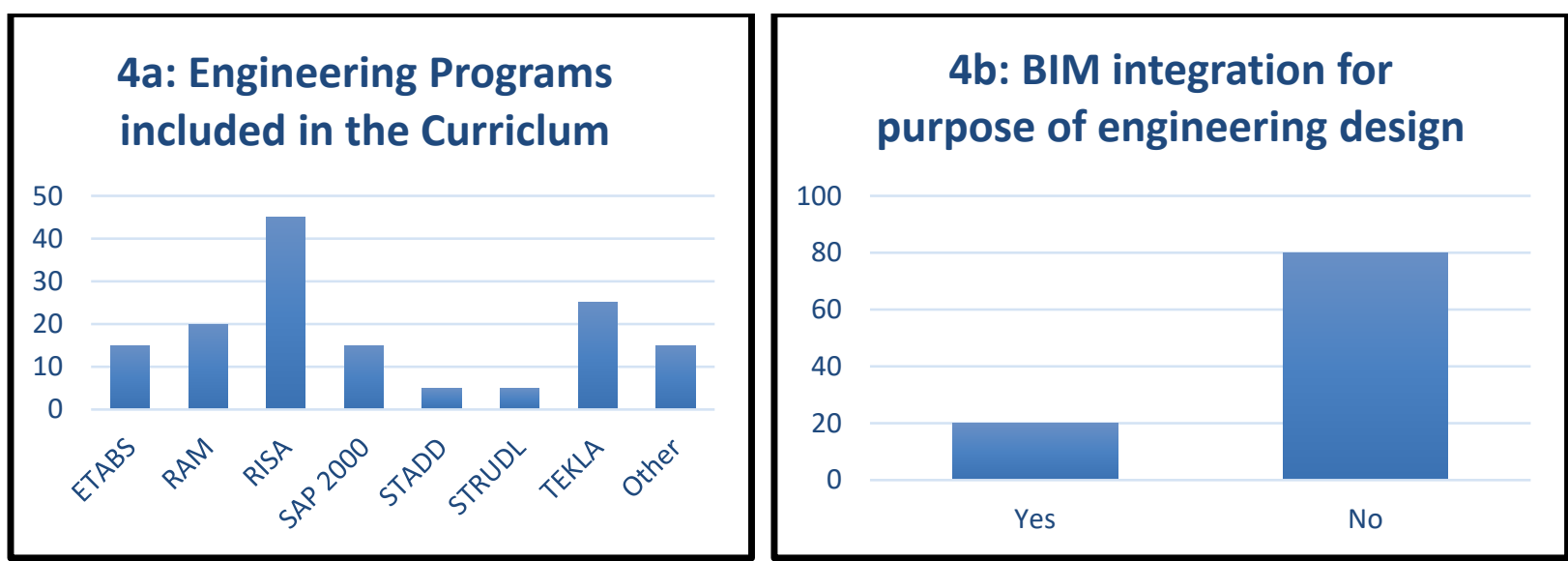

Figure 4a and 4b: Engineering program survey results on the inclusion of BIM and engineering programs

A further review of the survey results (Figures $4 \mathrm{a}$ and $4 \mathrm{~b}$ ) reveals the wide array of engineering analysis and design programs utilized in curriculums. RISA is the most widely used, and this too may be in part because of the low cost of licensing the program for universities. For the survey question on the use of integrating BIM for the purpose of structural design, only 20 percent of the respondents include this as part of the curriculum, which can be attributed to the lack of time available in the majority of programs to include and cover the topic.

For the survey sent to practicing structural engineering firms, a total of 24 firms were sent the survey, with all of the firms having offices in the United States, with several having international offices. Of those firms sent the survey, 18 responded to the survey. The results of the survey (Figures 5a and 5b) overwhelmingly indicated that engineers will utilize BIM upon entrance into the profession, and thus it can be concluded that students should be exposed to BIM during their education if possible.
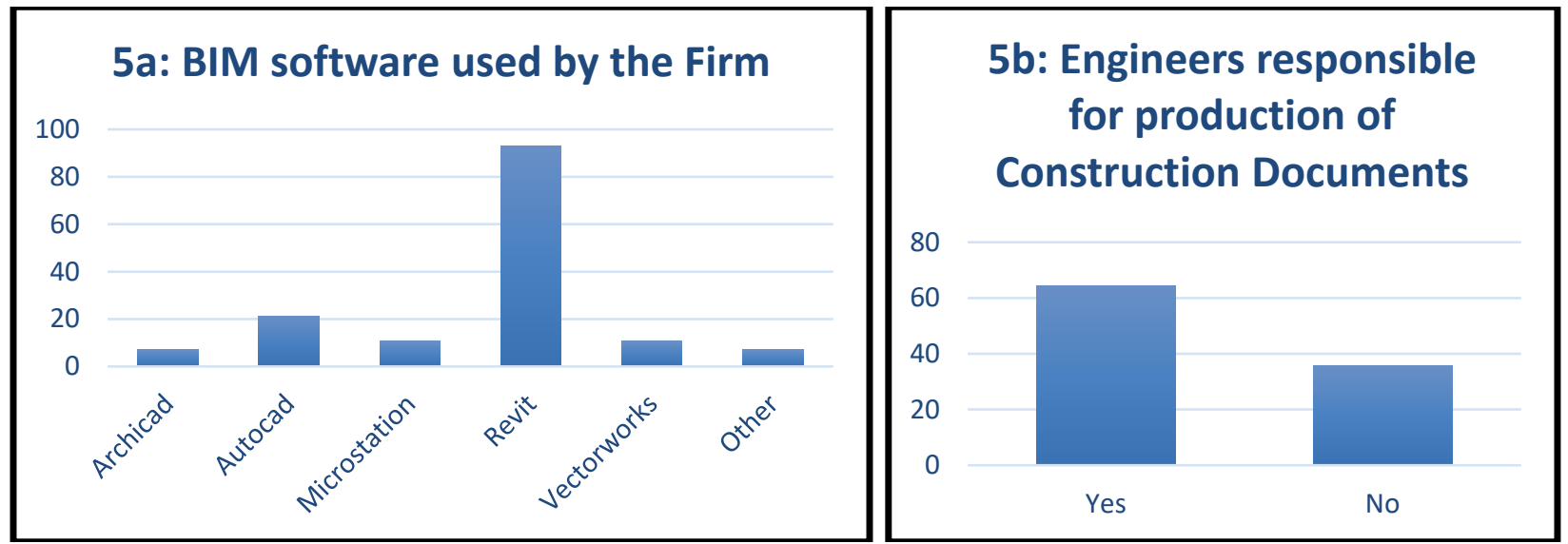

Figure 5a and 5b: Engineering firm survey results pertaining to BIM and structural engineering programs

From results of the survey of firms, fully 100 percent of the firms indicated that they utilize BIM as part of their professional practice, with Revit being the predominate program used in practice. As for 
whether the engineers are responsible for production of construction documents, a majority of the firms $(64 \%)$ indicated that engineers do take part in the production of construction documents.

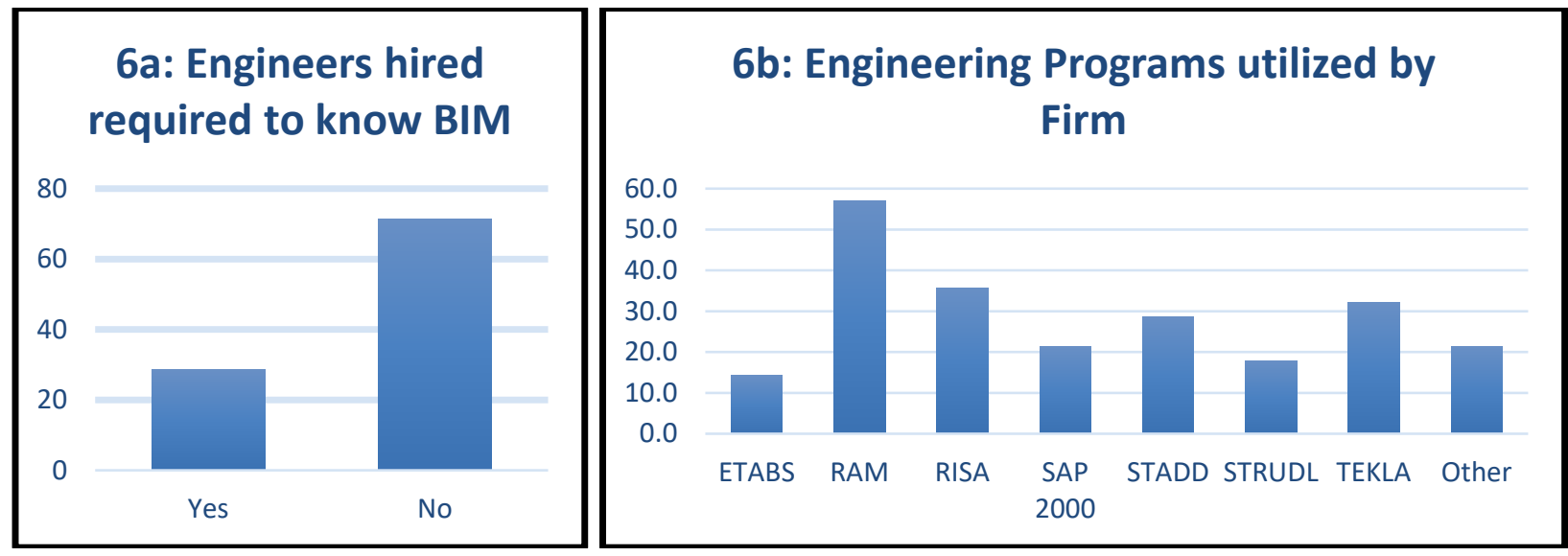

Figure 6a and 6b: Engineering firm survey results pertaining to BIM and structural engineering programs

Further, as indicated in Figure 6a, the majority of firms (71\%) indicated that those they hired as engineers were not required to know BIM, though a follow-up question suggested that knowledge of the program is important as $86 \%$ of firms required newly hired engineers to learn BIM if they do not know it when hired. In researching the structural engineering design programs utilized by firms, not surprisingly there were a number of different programs used. Many of these engineering design programs have the capabilities of interfacing with a BIM for the purpose of transferring a structural model between the software.

As a conclusion to the survey sent to practicing structural engineering firms, it is important to note that the results indicate that while the use of BIM for the purpose of documentation of a project is widely used, the use of BIM for the purpose of structural design is not used by most of the firms. Alternately, the majority of the firms utilize separate structural models for the purpose of engineering design, and in the authors' personal interactions with many of the firms has found that the interface between a BIM model and the engineering programs is cumbersome, not fully adaptable to individual firm standards, and many engineers lack total faith in the process. However, many of the firms do see that the interface is better with each version of the programs released, and can envision a day in the future when a BIM model will be able to be used for a building structures complete design and documentation process.

A third survey was given to students in both the Intermediate Steel Design and Intermediate Concrete Design courses to ascertain their assessment of employing BIM for the purpose of structural engineering of a multi-story building structure. The results shown on the following page in Tables $7 \mathrm{a}$ and $7 \mathrm{~b}$ are formatted on a 5 -point Likert scale $(1=$ strongly disagree, $5=$ strongly agree $)$ with the averages of the results presented. The statistical significance of the survey can be debated due to the limited number of students in each of the courses. Though each student enrolled in the course responded to the survey, there were only a total of five students enrolled in the intermediate steel course, and eight students enrolled in the intermediate concrete course. Regardless, the results of the survey are included to give an initial assessment of the incorporation of this technology into a classroom setting. Overall, the students responded positively to the inclusion of the new technology, and saw the relevance of utilizing the BIM model for the purpose of aiding in the structural design process. Additionally, results of the survey indicated that students see the relevance of BIM in the 
profession of structural engineering, and how the knowledge gained during their educational career will enhance their marketability and put them at the forefront of the evolving technologies utilized by the profession. They also felt strongly that learning programs in a classroom setting was favorable to learning them on their own.

\begin{tabular}{|l|c|l|l|}
\hline $\begin{array}{l}\text { Table 7a: Intermediate Steel Design: } \\
\text { Student Survey Results }\end{array}$ & $\begin{array}{l}\text { Table 7b: Intermediate Concrete Design: } \\
\text { Student Survey Results }\end{array}$ \\
\hline \multicolumn{3}{|c|}{ Results indicate average score with following responses: } \\
(1) Strongly Disagree (2) Disagree (3) Undecided (4) Agree (5) Strongly Agree \\
\hline $\begin{array}{l}\text { The use of BIM in the profession of } \\
\text { structural engineering will continue to } \\
\text { expand for the foreseeable future. }\end{array}$ & $\mathbf{5 . 0 0}$ & $\begin{array}{l}\text { Incorporating BIM in the curriculum is } \\
\text { important to engineering students who } \\
\text { will utilize the program upon entry into } \\
\text { the profession. }\end{array}$ & $\mathbf{5 . 0 0}$ \\
\hline $\begin{array}{l}\text { The inclusion of BIM is an important } \\
\text { aspect of the program and should } \\
\text { continue to be part of the curriculum. }\end{array}$ & $\mathbf{4 . 6 0}$ & $\begin{array}{l}\text { The time spent building the structural } \\
\text { model would be equal to time spent } \\
\text { building a BIM model and importing it } \\
\text { into the RISA-3D design program. }\end{array}$ & $\mathbf{4 . 5 0}$ \\
\hline $\begin{array}{l}\text { I prefer to learn programs used in my } \\
\text { profession on my own instead of being } \\
\text { taught them in a course. }\end{array}$ & $\mathbf{1 . 6 0}$ & $\begin{array}{l}\text { I prefer to learn programs used in my } \\
\text { profession on my own instead of being } \\
\text { taught them in a course. }\end{array}$ & $\mathbf{1 . 2 5}$ \\
\hline $\begin{array}{l}\text { BIM and structural engineering design } \\
\text { program interaction is worth exploring } \\
\text { in the curriculum. }\end{array}$ & $\mathbf{4 . 4 0}$ & $\begin{array}{l}\text { BIM and structural engineering design } \\
\text { program interaction is worth exploring } \\
\text { in the curriculum. }\end{array}$ & $\mathbf{4 . 7 5}$ \\
\hline $\begin{array}{l}\text { If integrated into the process of } \\
\text { structural engineering, BIM can } \\
\text { streamline and quicken the timeline for } \\
\text { design of the structure. }\end{array}$ & $\mathbf{3 . 4 0}$ & $\begin{array}{l}\text { If integrated into the process of } \\
\text { structural engineering, BIM can } \\
\text { streamline and quicken the timeline for } \\
\text { design of the structure. }\end{array}$ & $\mathbf{4 . 6 3}$ \\
\hline $\begin{array}{l}\text { Knowledge of BIM gives students an } \\
\text { advantage over other university } \\
\text { programs when searching for summer } \\
\text { and full time internships. }\end{array}$ & $\mathbf{4 . 8 0}$ & $\begin{array}{l}\text { Knowledge of BIM gives students an } \\
\text { advantage over other university } \\
\text { programs when searching for summer } \\
\text { and full time internships. }\end{array}$ & $\mathbf{4 . 7 5}$ \\
\hline
\end{tabular}

Tables 7a \& 7b: Students survey results on their perception of BIM in the field of structural engineering

\section{Course Enhancements based on Survey Results}

The inclusion of BIM in the curriculums of undergraduate and graduate engineering programs that focus on building structure design is necessary for the marketability of graduates to the profession. How much of this topic can be included in a programs curriculum is dependent largely on the length of the program, or whether there exists a graduate program as part of the offerings. Practicing engineering firms feel that BIM is an important topic and that it would be advantageous for newly hired engineering interns to know the program, though this is not a deal breaker in hiring the interns.

For the program at Oklahoma State University, the intent is to continue to demonstrate the power of the Revit to RISA link to students in the Intermediate Steel Design course as currently performed. For this beginning multi-story structural design and documentation course there is simply not enough time in the course, and the students do not know the BIM software well enough, for them to be responsible for developing a BIM model to interface with RISA. During this semester in the curriculum, students would not be fluent in Revit until the end of the semester, plus the focus of the course is on the use of RISA for the design process along with how building structures are documented for construction. 
Though there will be no changes in the Intermediate Steel Design course, this will not be the same for the Intermediate Concrete Design course. For that course, students will be required to build their own BIM model in Revit that can then be interfaced with the RISA design program. Students will be given the building parameters at the start of the course and will be required to build the model in Revit in the first two weeks of the course. Once complete and reviewed by the Professor, students will be taught the process for interfacing the BIM model with RISA to establish a structural model that can then be utilized for design. This revision will allow students to learn the process of multistory structural design and documentation in the first intermediate design course, and to experience and understand the efficiency available in utilizing a BIM model for the purpose of aiding the structural design process in the second intermediate design course. The results of this change will be assessed in future offerings of the course to determine if the change in the course format is positive.

\section{Conclusions}

The inclusion of advancing technologies in the education of engineering students is crucial when considering the needs of the profession and advancement of students' educational experiences. In teaching students the capabilities of Building Information Modelling integrated into the process of structural design, a major question is if or when to include the topic in the curriculum. Several points are apparent from the literary search performed and survey results for this research topic, including:

1. There are not many publications on research pertaining to the topic of incorporating the use of BIM into the process of structural engineering.

2. Few universities touch on the topic of BIM in their programs, and even fewer incorporate BIM with structural design programs. As the technology advances, it would be to the advantage of graduates of engineering programs to have some interaction with the power of the programs.

3. Practicing structural engineering firms are interested in the use of BIM for the production of construction documents, and largely want newly hired engineers to have experience with this modelling software.

4. Students understand the importance of BIM in the process of building design, and the advantage of utilizing the BIM model for the purpose of structural design.

For those undergraduate programs that are longer in duration, the opportunity to include this topic is more adaptable to the curriculum, whereas for shorter programs this would likely be considered as a topic that would be included in a graduate level course. An alternative would be to offer the topic in an elective course, allowing the students to be both more marketable upon graduation and at the forefront of the profession in stretching the limits of the available technologies. Revisions to the methods used to teach students the process of structural design and documentation for multi-story buildings will allow graduates to contribute to the profession as interns more quickly in the process of structural design. It is these types of technological advances that must continue to be introduced to students as part of their educational experience to help ensure that newly hired engineering interns can be productive members of engineering firms. The program at Oklahoma State University will continue to include the use of BIM in the process of structural engineering design and documentation, and will continue to explore research in this area in efforts to further advance the students' educational experience on the topic of Building Information Modelling, and how it can be used as an advantage in the process of structural engineering design. 


\section{References}

[1] R. Solnosky, "Opportunities for BIM to Enhance Structural Engineering Curricula", ASCE Structures Congress 2018, April 19-21, 2018, Fort Worth, Texas

[2] N. Hamza, and M. Horne, "Integration of virtual reality within the built environment curriculum”, Journal of Information Technology in Construction, 2006, 11. pp. 311-324

[3] Bates, Bruce R.; Primary author of RISA-3D Structural Analysis / Design Program, Computer program, 2004

[4] J. Phillips, "Multi-Story Steel Structures: Making Sure Students Understand the Design Process" 2007 ASEE Annual Conference and Exposition, Honolulu, HI, June 24-27

[5] J. Phillips, "Current trends in Architectural Engineering Education" Proceedings from the 2018 ASEE Annual Conference and Exposition, Salt Lake City, UT, June 24-27 